Bryn Mawr College

Scholarship, Research, and Creative Work at Bryn Mawr College

Education Program Faculty Research and

Scholarship

Education Program

2018

\title{
Articulating identities and analyzing belonging: a multistep intervention that affirms and informs a diversity of students
}

Alison Cook-Sather

Bryn MawrCollege, acooksat@brynmawr.edu

Let us know how access to this document benefits you.

Follow this and additional works at: https://repository.brynmawr.edu/edu_pubs

Part of the Education Commons

\section{Custom Citation}

Cook-Sather, A. 2018. "Articulating identities and analyzing belonging: a multistep intervention that affirms and informs a diversity of students." Teaching in Higher Education 23.3: 374-389.

This paper is posted at Scholarship, Research, and Creative Work at Bryn Mawr College. https://repository.brynmawr.edu/edu_pubs/36

For more information, please contact repository@brynmawr.edu. 


\title{
Articulating Identities and Analyzing Belonging: A Multistep Intervention that Affirms and Informs a Diversity of Students
}

\author{
Alison Cook-Sather, Crystal Des-Ogugua, and Melanie Bahti
}

\begin{abstract}
This article describes a multistep intervention developed for an undergraduate course called 'Advocating Diversity in Higher Education.' The goal of the intervention was to affirm diversity and foster a sense of inclusion among students within and beyond the course. We contextualize the intervention in student protests during 2015 and 2016 regarding racial and other forms of discrimination on college and university campuses in the United States, and we describe how it is informed by several theoretical frames and associated practices: intersectionality, belonging, and radical pedagogical partnership. Co-authored by the faculty member who co-designed and co-taught the course, an undergraduate student who co-designed the course, and a recent graduate who cocreated the course when she took it, the article embodies the inclusion and radical partnership it analyzes. It is intended to offer individuals working in higher education an intervention that can be adapted across contexts.
\end{abstract}

Key words: diversity, intersectionality, belonging, pedagogical partnership

\section{Introduction}

Student protests at colleges and universities across the United States in 2015 and 2016 attempted once again to raise awareness of discriminatory histories and persisting structural inequities on campuses and in the country. Some of these protests focused on discrimination long experienced by Black students, while others endeavored to raise awareness of prejudice experienced by other students also traditionally underrepresented in, and underserved by, higher education. These protests spurred members of institutions of higher education at all levels - administrative, departmental, and individual - to intensify their efforts to address and redress legacies of racial and other injustice and to create structures and practices that honor a diversity of people.

In this article we describe one such effort: a multistep intervention developed in relation to an undergraduate course called 'Advocating Diversity in Higher Education' and designed to affirm diversity and foster a sense of inclusion among students within and beyond the course. We write with a single voice informed by our respective positions. Alison is a white, female, tenured faculty member with 25 years of teaching experience and ten years of experience directing Students as Learners and Teachers (SaLT). SaLT is a program at Bryn Mawr and Haverford Colleges that pairs undergraduate students and faculty in semester-long pedagogical partnerships (Cook-Sather 2014). Crystal is a Black woman, an undergraduate sociology major and Africana Studies minor at Bryn Mawr College, a Mellon Mays Fellow, and a student consultant in SaLT. Melanie is a white woman, a recent graduate of Bryn Mawr College with a major in linguistics, and a former SaLT student consultant who now works in educational technology. We have collaborated for three years, on and off campus, to support the creation of more inclusive pedagogical structures and practices that contribute to a sense of student belonging.

The intervention was conceptualized as part of Alison's and Crystal's co-design in the Fall2015 semester of 'Advocating Diversity in Higher Education.' During this first step, Crystal invited 
16 members of the campus community who claim a diversity of identities to participate in one-onone, structured interviews through which they named the dimensions of their identities and how those shape how they navigate the social and political landscapes of their campuses. The second step, also part of Alison's and Crystal's co-design process, drew on students' own words from the interviews, which Crystal used to compose anonymous but detailed articulations of the individual student experiences, verbal portraits, which became required reading for the course. The third step was the creation by Crystal of a template for use as one option for the fieldwork component of the course. This is the option Melanie took up as one of 20 students who enrolled in the course. Step four was the completion by Melanie (and other students enrolled in the course) of additional interviews, using and modifying Crystal's template, that also became required reading for the course.

The goal of the intervention was to access the experiences students have at the intersections of their academic experience (fostered in and outside the classroom), their social experience, and their personal backgrounds, experiences, and identities that shape them outside the campus. In particular, our goal was to create a forum for marginal voices to be heard and respected by putting them in a place where they can inform classroom pedagogy and student learning. Our discussion in this article focuses on the conceptualization, structure, and use of the intervention, not on the individual identities of students who were interviewed.

To evoke the context in which we conceptualized the intervention, we begin by providing an overview of student protests in 2015 and 2016 and reviewing some of the ways in which institutions in the United States have responded to increasing student diversity and related student protests. We then outline the theories and associated practices that informed the development of the intervention: intersectionality, belonging, and student-faculty pedagogical partnership. Next we offer a brief discussion of our methods. The majority of the article is devoted to a detailed description and analysis of how the intervention was designed during the course preparation phase and then further developed as one of the options for the fieldwork assignment for 'Advocating Diversity in Higher Education.' We conclude with a call to create more such structures and practices that honor a diversity of people.

\section{Context: Student Protests and Institutional Responses}

In recent years, college campuses across the United States have experienced a resurgence of student protests (Jaschick 2016; New 2016). This movement has been evident on 'large campuses and small, elite and not-so-elite institutions, campuses with strong histories of student activism and not' (Jaschick 2015). The American Freshman Survey, which collected responses from more than 141,000 first-year students during their first few weeks of college in 2016, found, among other things, 'renewed interest in civic and political engagement' and a rise in student activism (New 2016).

These are responses to the long legacies of discrimination and structural inequality that have impacted students' identification with and sense of inclusion in or exclusion from the institutions they attend. Not isolated phenomena of today, the most recent protests are iterations of past student movements intended to challenge the isolating institutional structures that shape students' past and present marginality within those institutions. Indeed, as with many of the protests in the 1960s and 1970s, 'the current wave of student protest has been generated by, and is entwined with, national concerns, particularly racism, sexual violence, and growing inequality (Volk 2017). 
The resurgence of such marginal-student movements falls in line with the significant shifts in student demographics on university and college campuses across the country that have resulted from federal and state governments having adopted the principle of increasing access through programs like the GI Bill, direct state subsidies, the Pell Grant and various federal loan programs (Mitchell 2014) and from institutional commitments to increasing diversity (e.g., AAC\&U n.d., AAUP n.d.).

Administrators' responses to the protests and increased student activism have typically been to form task forces and to appoint chief diversity officers. These institutional responses are important for the ways they put 'diversity into the places that are already valued so that diversity can come into view' (Ahmed 2014, 30). At the same time, however, there is a way in which 'the creation of new roles and appointments to them actually signal a cordoning off of commitment rather than an institutional goal of diversity' (Ahmed 2012, 23). As administrators wrestle with what constitutes a meaningful institutional commitment to diversity and how higher education might measure inclusivity (Wexler 2016), individual faculty members and students have taken steps toward affirming diversity and fostering a sense of inclusion and belonging. The intervention we describe here was our attempt to bridge the gap between varyingly successful institutional efforts and student desires and need, to realize the generative potential of students and faculty collaborating to make changes within the institution, and to take advantage of the agency our institutional roles afforded us.

\section{Theoretical Frames and Approaches}

The project we developed was informed by three theoretical frames: intersectionality, belonging, and pedagogical partnership. Each of these argues and creates forums for marginal voices to be heard and respected by putting them in a place where they can inform classroom pedagogy and student learning. Each recognizes and honors the complexity of identity, the centrality of relationship, and the necessity of informed collaboration in higher education.

Intersectionality is a term coined by Crenshaw (1989), who used it to underscore the “"multidimensionality" of marginalized subjects' lived experiences (Crenshaw, 1989: 139)' (quoted in Nash 2008, 1). Crenshaw $(1991,1245)$ subsequently argued that her focus on the intersections of race and gender 'highlights the need to account for multiple grounds of identity when considering how the social world is constructed.' Because intersectionality 'subverts race/gender binaries in the service of theorizing identity in a more complex fashion' (Nash 2008, 2), it is helpful in highlighting that 'social inequality is not only determined multidimensionally along different axes of inequalitysuch as gender, migration, socioeconomic background, age, disability, and so on-but emerges particularly in the intersection of these axes as they mutually constitute each other within social contexts' (Gross, Gottburgsen, \& Phoenix 2016, 51).

In the realm of education, intersectionality has emerged to capture the reality that 'the people on our campuses - the students, faculty, and staff - do not encounter diversity in the fractured ways that match the organizational structures of our institutions' (Barnett \& Felten 2016, xv). Both individuals and institutions need to recognize that multiple dimensions of identity inform each of us in every situation and also change across contexts and evolve over time. Intersectionality is 'rooted in the premise that understanding identity, oppression, power, and marginalization cannot be accomplished by looking solely at single identities' (Barnett \& Felten 2016, xvi; see also Mitchell, Simmons, \& Greyerbiehl 2014). The intervention we developed strove to honor the intersectionality 
of members of the campus community and invite them to articulate their identities in their own words and analyze the ways in which they experience institutional structures and practices.

Belonging is likewise gaining more attention on college campuses. A good deal of research shows that students from 'at-risk and nondominant groups often feel a profound sense of both social and academic nonbelonging when they arrive on campus' (Barnett \& Felten 2016, 9-10). This experience can persist and become exacerbated if peers, faculty, and others on campus respond to underrepresented students in negative or insensitive ways. Belonging uncertainty, 'doubt as to whether one will be accepted or rejected by key figures in the social environment,' can 'prove acute if rejection could be based on one's negatively stereotyped social identity' (Cohen \& Garcia 2008, 365) and can result in 'a distrust of nonminority students and university officials' (Simmons et al. 2013, 2; see also Hurtado et al. 1998) as well as faculty. The goal of our interview project was to foster a sense of belonging through bringing the voices of marginalized students into a classroom-based discussion of advocating diversity in higher education, showing those students that their voices and experiences matter.

Strayhorn $(2012,3)$ has argued that in order for students to feel a sense of belonging, students need to experience a 'feeling or sensation of connectedness' and have 'the experience of mattering or feeling cared about, accepted, respected, valued by, and important to the group (e.g., campus community) or others on campus (e.g., faculty, peers)' (see also Asher \& Weeks 2014). Within the context of our course and the interviews Crystal conducted, belonging was fostered through the formal and informal interventions created by underrepresented students and ally faculty. The classroom was a space where students could create and define belonging on their own terms, and the interviews captured how students of color and other underrepresented students found and created belonging in institutional spaces that did not recognize or marginalized them. Rather than only emphasize the inclusion of underrepresented students by the dominant group on campus, the intervention we developed focused on how a sense of belonging for these students can be fostered through the dismantling of the oppressive systems that relegate them to the margins of the institution.

Our third frame and approach is pedagogical partnership, which is gaining momentum as one approach to recognizing, valuing, and drawing on the multiple experiences and perspectives that students and faculty bring to the educational endeavor (Cook-Sather \& Felten 2017b; Healey, Flint, \& Harrington 2014; Matthews 2016). During the course co-design phase in which we developed our intervention, we focused on generating curriculum and course materials that would recognize students' intersectionality and foster a sense of belonging. A partnership approach to curriculum design can make explicit and address power imbalances and notions of expertise among those involved in a learning experience (Bergmark \& Westman 2016; Bovill 2014; Mihans, Long, \& Felten 2008) and serve to promote a sense of belonging and empowerment (Matheson \& Sutcliffe 2016).

Co-creation of course materials both creates spaces for student engagement and strives to enact a more democratic process of learning. Such an approach is particularly important for students from underrepresented backgrounds, who have found that participating in partnership can counter the belonging uncertainty they experience. As one student from an underrepresented group explained, participating in student-faculty pedagogical partnership 'made me feel like who I am is more than enough - that my identity, my thoughts, my ideas are significant and valuable' (CookSather 2015; see also Cook-Sather \& Agu 2013). 
During both the co-planning and the classroom-based co-creation phases of 'Advocating Diversity in Higher Education,' as we experienced and watched the toll that ongoing protest takes on students (Ruff 2016), we had as our priority to affirm a diversity of students in the [name of colleges] communities and to inform all members of the course regarding those students' identities and experiences of belonging or alienation. This approach complements recent discussions of utilizing students' funds of knowledge as assets for disciplinary learning (Daddow 2016) by using those sources for co-creation and for education regarding identities as well.

\section{Methods}

During and after the unfolding of 'Advocating Diversity in Higher Education' in the Spring-2016 semester, we described the interview project to colleagues at multiple institutions. Encouraged by their enthusiastic responses, we decided to draw on our own reflections and to follow up with some of the students interviewed for the course to write an analysis for a wider audience.

In addition to providing excerpts from their original interviews, students whom Crystal and Melanie had interviewed before and during the Spring-2016 semester addressed this question: 'In what ways, if any, did participating in the interview process make you feel that your voice and experience are important in and of themselves and also to understanding and advocating diversity in higher education?' Excited that their experiences and words would reach readers beyond the college community, all students quoted in this discussion gave written permission for their words to be included in the article.

Drawing on excerpts from students' original interviews and responses to the question above, we employed narrative analysis, which 'seeks to put together the "big picture" about experiences or events as the participants understand them' (Schutt 2016, 194). Rather than delve into analyses of individual students' identities, we focus on explaining the structure of the intervention and share glimpses of students' experiences of participating in the interviews. We hope that the inclusive reach of the intervention might have positive outcomes for those beyond the course and prompt our own and other institutions to take similar approaches. In this way, the project becomes both an intervention in our own context and a template for interventions in other contexts and a form of action research — collective, self-reflective, critical inquiry (McCutcheon \& Jung 1990) that integrates action and research to challenge the routines of the status quo (Somekh \& Zeichner 2010).

\section{Co-creating the Interview Project during Course Preparation}

The approach Alison and Crystal took to co-designing 'Advocating Diversity in Higher Education' included meeting weekly to discuss the goals, resources, and assignments. While we worked through all components of the course together, our focus in this discussion is on the multipart interview project. As we have noted, the goal of the project was to affirm diversity and foster a sense of inclusion, and our focus in this section of our discussion is on our rationale for and approach to developing a structure for inviting articulation of diverse dimensions of students' identities. We share excerpts from interviews to highlight the diversity of identities students bring, but we do not delve into analysis of those identities.

Developing the Interview Project 
Created by Crystal and refined through dialogue with Alison, the structure for one-on-one, confidential interviews was developed to combat erasure of marginal voices and identities in the classroom. In the context of the interviews, Crystal invited students in the wider college community to name their identities and how they experienced belonging and/or alienation within and beyond their college classrooms. By creating a forum within which students could, in confidence, articulate their identities - choose their own words for how to name who they are-and analyze how they do and/or do not experience a sense of belonging on these campuses based on these identities, we hoped to bring them into being/presence in the classroom.

Crystal wanted the interviews to function as spaces of dialogue in which each student's identity and its intersections were positioned as central to constructing an understanding of that person's experience of their campus. Before embarking on the interviewing process, Crystal's initial goal was to generate a sequence of questions that would guide her facilitation of such a space where an identity-informed perspective could be honed in on through the interview process. In the interview process itself, Crystal started by inviting the student to list their identities and their intersections, and she ended with asking students what they believe is necessary for change. Such an intentional movement within dialogue allows students to articulate their lived realities on campus in ways that emphasize how their navigation of/encounters with identity inform what they believe to be their institution's orientation and goals regarding diversity.

Once the initial outreach was done, Crystal was intentional about reaching out to a vast range of students to capture the breadth of the student experience in our bi-college context. This meant reaching out to students from both over- and underrepresented groups on campus to document the complex image of how identity informs the student experience of campus. Once in dialogue with students, Crystal found that they relaxed into the security/comfort of the veil of ambiguity and let themselves be guided by the structure of the questions.

\section{The Interview Project as Course Content}

Crystal then shaped these interviews into anonymous but detailed 'portraits' that became required reading for 'Advocating Diversity in Higher Education.' Periodically throughout the course, the class would read collections of these interviews, either prior to meeting or in 'Gallery Walks' (that featured hard copies of the interviews posted around the classroom and students walking around and reading them during the class session itself). In both cases, the challenge Alison posed to all students enrolled in the course was to tune their ears — and their hearts and minds (Delpit 1988) — to value all the voices and experiences represented.

Through the iterative process of reading, reflecting on, and talking about the diversity of voices and experiences captured in the portraits, students enrolled in the course did indeed tune their ears, hearts, and minds to heed both familiar and unfamiliar, affirming and destabilizing voices. The Gallery Walks were among the activities students most often mentioned in informal and end-ofsemester feedback on the course as having a profound effect on how they think about identity, diversity, and belonging. They consistently described how the listening skills, and the insight into and respect for differences, they developed through this component of the course inform their interactions with others beyond the course and even beyond the college. Students who found their voices and experiences reflected in the narratives in the Gallery Walks experienced solidarity, 
visibility, and validation. When students could not identify with or even understand the differences they encountered in the portraits, they deepened their commitment and capacity to honor them.

The portraits revealed that students have profoundly different experiences of the campus. For instance, one student reflected on feeling unable to be herself:

I don't match. On campus I feel like I have to put up a facade, and walk around with it so people don't 'fuck with me.' I use it to protect myself, because as soon as I let it down, I feel like my identity will be attacked. I also sometimes feel like there is a stigma associated with the use of colloquial vocabulary. I always find myself having to bite off/cut off my tongue to feel respected in this community. [nterview 2]

In contrast, another student said:

I am white, I am upper class. This makes any space easier for me to navigate. In the classroom or campus spaces, I don't have to worry that my actions will be reflective of my entire race. I also never have to worry about money. I have a job, but I don't need it. I can participate in events on and off campus without money. I don't have to worry about public safety profiling me or confronting me. The issues [I experience] pale in the shadow of the obvious privilege I experience on a day-to-day basis at [initials of college].

[Interview 10]

These contrasting experiences point to how the campus space is constructed for certain bodies. Even those who feel as though the space is made for them can find ways of complicating that phenomenon.

Regardless of how they feel on campus, the students who were interviewed felt affirmed by the attention to issues of diversity that otherwise could feel like individual weights to carry, and that the interviews gave them 'space' to realize that. In one student's words:

Participating in the interview gave me the time and space to realize that the issue of diversity is also an issue that does exist outside of my headspace. I think it's so easy to blame myself for the way that things are; like accepting the heteronormativity spaces or going along with the 'white expectations' in many spaces and situations on campus. As a senior, I now know the spaces that make me comfortable, where I don't have to perform and know the people who also build me to my truest forms. And hopefully that doesn't mean that I always avoid spaces that are white majority but can make the choice to be in that space and know the set expectations that those spaces can bring.

Another student contrasted an experience she had over the winter break in Los Angeles with her experience of having lived in New Jersey and at [name of college], which she experienced as 'white majority with some "different people." Los Angeles, in contrast, was 'truly the experience of America that I have never before had...It was an experience where everyone owned their identities and embraced others for their beings.' In this context, she found, 'People seemed to absorb knowledge from each other through conversations and by asking questions.' Linking that winter experience to the interview in which she engaged with Crystal, this student explained: 
From this experience, I realize that understanding and advocating diversity in higher education is more than important for the entire community and that it can start from all aspects of the community. One aspect would be creating spaces ourselves to talk about the differences and not be afraid to learn and ask questions. We are often so resistant to ask questions because we want to be politically correct, but how can we be politically correct if we don't know anything? I think that is how it becomes a cycle of ignorance, which can be toxic for anyone in the community.

These students' emphasis on the importance of creating spaces to talk about differences, asking questions, and listening, reaffirmed the importance of the interview project not as a space to focus on particular differences but rather as a structure that invited all students to articulate and affirm their own identities.

\section{Co-creating the Intervention as Optional Fieldwork Assignment}

In a radical partnership approach similar to the co-creation in which Alison and Crystal engaged in designing 'Advocating Diversity in Higher Education,' Alison invited all students who chose to enroll in the course to co-create it as it unfolded. Each student completed a Course Commitment form that listed course requirements, and each student chose how to fulfill those requirements and how much each would count toward their grade. They selected their own readings, developed their own topics for research projects, and chose the form their fieldwork would take (Cook-Sather \& Des-Ogugua 2017). All students also self graded, based on their Course Commitment forms. Crystal was studying abroad during the semester during which the course was taught, but she stayed in touch via email and thus remained a partner as the course unfolded.

To support students in pursuing the option to conduct their own interviews and create their own portraits, Crystal crafted an assignment that offered step-by-step instructions for conducting the interviews and creating the portraits. (See Appendix I.) Students who chose this option completed one interview and portrait per week, and the portraits became required reading for the course.

Melanie was one of the students enrolled in the course who chose to complete the interview assignment, but she approached this assignment in a slightly different way from how it was originally conceived: she created new questions that focused on individual students' experiences of inclusion and exclusion in their learning environments (which mostly meant in the classroom). Melanie had been exploring strategies for promoting inclusive classroom environments during a student-faculty partnership through the SaLT program, and shifting the direction of the assignment for 'Advocating Diversity in Higher Education' allowed her to continue pursuing her interest in inclusive pedagogy. At the same time, the focus of the interview assignment on individual experience allowed the students she interviewed to speak from their own perspectives, which gave them a space to tell their story similar to the space created by the original set of interview questions.

When Melanie designed the questions she used for her version of this assignment, she structured them in a similar way to the original set in that she asked the students she spoke to not to tell her about individuals but rather to speak about experiences, strategies, and practices that contributed to their feeling included or excluded in learning environments. This approach frames the conversations in a different light and establishes a different kind of discourse than one might hear in 
a casual conversation about someone's negative (or positive) classroom experiences. By focusing on actions rather than on individuals, Melanie found that the students she spoke to were very constructive in their comments, celebrating particularly positive strategies and offering alternatives to practices that created exclusionary environments. These responses are powerful in their own right, and their constructiveness suggests that questions framed in a similar way can elicit actionable insights to improve students' experiences of belonging in higher education environments.

Melanie's approach to this assignment was informed in several ways by the co-creation process that shaped 'Advocating Diversity.' Because students enrolled in the course had many options for completing a fieldwork component of the course, they were able to shape their choices to align with personal interests and goals for engagement with campus communities. As Melanie shaped her interview questions, she participated in a co-creative relationship with both Alison and Crystal. Alison offered students flexibility and space to design their own fieldwork projects, which informed and were informed by other course content. And although Crystal was not physically present in Melanie's class, the structure and intention of her original assignment and interview portraits provided the framework for Melanie's fieldwork.

The process of conducting the interviews offered its own form of co-creation. While Melanie developed a set of questions prior to conducting her first interview, these questions shifted over time in response to the ideas and perspectives of participants. Each conversation shifted her own viewpoint and gave her new ideas to consider. She interviewed only six students, and yet the range of strategies, suggestions, frustrations, celebrations, and insights she heard was amazing and thought provoking. Conducting the interviews offered a window into what it might be like if every member of the community had a space to share their experience. The ability to adjust interview questions over time allowed participants to be in dialogue with previous respondents' ideas and insights.

A particular insight these interviews yielded, which prompted the addition of a question to Melanie's list, is the power of students advocating for one another. Students are often set up to view peers as competitors for grades, attention, etc., and this can lead to a reluctance to be 'on the same team,' as one of her interviewees put it. Many of the students Melanie talked to mentioned ways that they had advocated for one another in their classes, and while it should not be solely students' responsibility to create inclusion in the classroom, creating a culture of student peer advocacy would have a positive impact.

The insights Melanie interviewees offered provide interesting approaches to addressing some of the issues that Crystal's interviewees articulated: validating students' experiences and creating inclusive conversations. For instance, focusing on having her experience recognized and affirmed, once interviewee explained:

The interview process didn't so much make me realize that my voice was important as it did make me feel like academia was catching up to me, in a way. I already had a sense that my experiences in the classroom were real and true, and so when I participated in the interview it was almost hard to talk about because everything had been so normalized to me in a way that felt obvious.

This same interviewee also focused on how an intervention like this contributes to understanding and advocating diversity in higher education: 'I did have a sense that recording my experiences was a 
vital step in advocating for support for students in diverse communities which hadn't happened yet, and that was very exciting.'

Another one of the people Melanie interviewed emphasized the importance of what happens in classrooms to affirm, or undermine, students' sense of belonging:

Participating in the interview process made me feel that my voice and experience are important to understanding and advocating diversity in higher education because the questions I was asked allowed me to think deeply about the obvious yet minute ways in how diversity can be allocated for. It gave me the space to actually reflect and process all the tools and methods that allowed me to feel like I was a part of the inclusive yet dynamically growing community.

This person saw the intervention not only as an opportunity to analyze what was already happening but also to consider what could happen:

It also allowed me to stop and think about ways it can improve and what other ways we can expand on to the previous, established strategies. So, always being able to tie things to the larger picture of creating a continuously, growing/evolving experience metaphorically as well as think about how to add to the classroom structure is great. This helped me notice a lot of things from a student perspective but also allowed me to remove myself and be a third person that analyzes the situations more in depth.

The interview as both fieldwork for the course and intervention in the wider campus community raised awareness, affirmed a diversity of experiences and voices, and extended the co-creation through which the intervention was created.

\section{Conclusion}

Both the interviews Crystal conducted that became course content and the interviews Melanie conducted to extend and fulfill a course assignment gave students a space where they felt a sense of 'connectedness' because they felt listened to, valued, and respected (Strayhorn 2012). By making space for student voices in conversations about identity, inclusion, and belonging, the interview project affirmed that student input belongs in the dialogue about diversity on college campuses. This affirmation, especially when echoed in broader institutional projects, can serve to address students' sense of nonbelonging within the institution (Barnett \& Felten 2016). The interviews also brought the presence, experiences, and voices of a range of students into the classroom, both affirming some typically marginalized identities and challenging all students to receive and engage what these individuals were articulating. Such work, taken alongside administrative efforts at the institutional level, can name and work against the long discriminatory histories and persisting structural inequities in higher education.

In many educational and social respects, the university functions as a microcosm of the social world it is created to serve and, in some cases, change. The reflexive relationship between school and society makes it incumbent upon institutions of higher education not to perpetuate the hierarchical, and oftentimes oppressive, systems of society. Within this context, an institutional 
project that works towards facilitating inclusion on campus must consider the degree to which the experience of intersecting identities on campus is mediated and informed by the social value inscribed in a student's identity outside the walls of the institution. This perspective of identity evokes a definition of institutional responsibility that locates an introspective assessment of how it reproduces and legitimizes exclusion at the center of efforts towards inclusion. Such projects of inclusivity not only strive to increase representation and diversity, but also recognize the importance of providing structural support for that goal, thereby making accessibility more than just a call for inclusion, but rather, a generative invitation for revision.

As a smaller more 'manageable' version and representation of society, the institution has the potential to be the site of innovative change. If we think of higher education, individual courses, and pedagogical partnerships as 'as-if' places (Walker 2009, 221), places 'where long term goals of social change are lived inside the institution as if they were already norms for society' (Bivens 2009, 3), we can use those spaces to behave the way we want to live in the wider world (Cook-Sather \& Felten 2017a). Each of these 'as-if,' liminal spaces can become what hooks $(1990,342)$ calls " the site of radical possibility, a space of resistance"” (quoted in Green \& Little 2013, 525). Within such spaces we cam cultivate 'expanded moral sympathies, deepened democratic dispositions, and a serious sense of responsibility for the world' (Hansen 2014, 4). If students, faculty, administrators, and the institution as a whole work in partnership to actualize changes in a bounded space, it provides these actors with the tools to create change in the 'outside world.'

Stated word count: 6,996

\section{References}

AAC\&U (n.d.) Diversity, Equity, and Inclusive Excellence. https://www.aacu.org/resources/diversity-equity-and-inclusive-excellence

AAUP (n.d.). Diversity and Affirmative Action. https://www.aaup.org/issues/diversity-affirmativeaction

Ahmed, S. (2012). On Being Included. Durham, NC: Duke University Press

Asher, S. R., \& Weeks, M. S. (2014). "Loneliness and Belongingness in the College Years." In The Handbook of Solitude: Psychological Perspectives on Social Isolation, Social Withdrawal, and Being Alone. First Edition. Edited by R. J. Coplan \& J. C. Bowker, 283-301. John Wiley \& Sons, Ltd.

Barnett, B., \& Felten, P. (2016). Intersectionality in Action: A Guide for Faculty and Campus Leaders for Creating Inclusive Classrooms and Institutions. Stylus Publishing.

Bergmark, U., \& Westman, S. (2016). Co-Creating Curriculum in Higher Education: Promoting Democratic Values and a Multidimensional View on Learning. International Journal for Academic Development 21(1): 28-40.

Bovill, C. (2014). An Investigation of Co-created Curricula within Higher Education in the UK, Ireland and the USA. Innovations in Education and Teaching International 51 (1): 15-25.

Cohen, G. L., \& Garcia, J. (2008). Identity, Belonging, and Achievement: A Model, Interventions, Implications. Current Directions in Psychological Science, 17(6): 365-369.

Cook-Sather, A., (2015). Dialogue across differences of position, perspective, and identity: Reflective practice in/on a student-faculty pedagogical partnership program. Teachers College Record, 117, 2.

Cook-Sather, A., (2014). Multiplying Perspectives and Improving Practice: What Can Happen When Undergraduate Students Collaborate with College Faculty to Explore Teaching and Learning. Instructional Science 42: 31-46. 
Cook-Sather, A., \& Agu, P. (2013). Students of color and faculty members working together toward culturally sustaining pedagogy. In J. E. Groccia \& L. Cruz (Eds.), To improve the academy: Resources for faculty, instructional, and organizational development (Vol. 32, pp. 271-285). San Francisco, CA: Jossey-Bass.

Cook-Sather, A \& Des-Ogugua, C. (2017, February). Invited Workshop, Lafayette College, PA.

Cook-Sather, A, \& Felten, P. (2017a). Cosmopolitan Perspectives on Becoming an Academic Leader in Higher Education. London: Bloomsbury.

Cook-Sather, A \& Felten, P. (2017b). Where student engagement meets faculty development: How student-faculty pedagogical partnership fosters a sense of belonging. Student Engagement in Higher Education Journal.

Bivens, F. (2009). Visioning a Human Rights Based Approach to Higher Education. GUNI Newsletter 39(26): 2-4.

Crenshaw, K. (1989). Demarginalizing the Intersection of Race and Sex: A Black Feminist Critique of Antidiscrimination Doctrine, Feminist Theory, and Antiracist Politics. University of Chicago Legal Forum 139.

Crenshaw, K. (1991). Mapping the Margins: Intersectionality, Identity Politics, and Violence against Women of Color. Stanford Law Review 43(6): 1241-1299.

Daddow, A. (2016). Curricula and Pedagogic Potentials When Educating Diverse Students in Higher Education: Students' Funds of Knowledge as a Bridge to Disciplinary Learning. Teaching in Higher Education 21(7): 741-758.

Delpit, L. (1988). The Silenced Dialogue: Power and Pedagogy in Educating Other People's Children. Harvard Educational Review 58(3): 280-298.

Green, D. A., \& Little, D. (2013). Academic Development on the Margins. Studies in Higher Education 38(4): 523-537. DOI: 10.1080/03075079.2011.583640

Gross, C., Gottburgsen, A., \& Phoenix, A. (2016.) "Education Systems and Intersectionality." In Education Systems and Inequalities: International Comparisons, edited by Andreas Hadjar and Christina Gross, 15-72. Bristol: Policy Press.

Hansen, D. T. (2014). Cosmopolitanism as Cultural Creativity: New Modes of Educational Practice in Globalizing Times. Curriculum Inquiry 44(1): 1-14.

Healey, M., Flint, A., \& Harrington, (2014). Engagement through Partnership: Students as Partners in Learning and Teaching in Higher Education. Higher Education Academy.

hooks, b. (1990). “Talking Back." In Out there: Marginalization and contemporary cultures, edited by R. Ferguson, M. Gever, T.T. Minh-ha, and C. West, 337-43. Cambridge, MA: MIT Press.

Hurtado, S., Milem, J. F., Clayton-Pedersen, A. R., \& Allen, W. R. (1998). Enhancing Campus Climates for Racial/Ethnic Diversity: Educational Policy and Practice. The Review of Higher Education 21(3): 279-302.

Jaschick, S. (2016, November 17). Tensions, Protests, Incidents. Inside Higher Ed. https://www.insidehighered.com/news/2016/11/14/protests-and-incidents-spreadfollowing-trump-election-victory?mc cid $=106 \mathrm{~b} 089001 \& \mathrm{mc}$ eid=9f3fa7023d

Jaschik, S. (2015, November 16). What the Protests Mean. Inside Higher Ed. https://www.insidehighered.com/news/2015/11/16/experts-consider-what-protests-overracial-tensions-mean?utm source $=$ Inside + Higher + Ed\&utm campaign $=9 \mathrm{bc} 310 \mathrm{~d} 4 \mathrm{e} 7-$ DNU20151116\&utm medium=email\&utm term $=0$ 1fcbc04421-9bc310d4e7-197314581

Matheson, R., \& Sutcliffe, M. (2016). Creating Belonging and Transformation through the Adoption of Flexible Pedagogies in Masters level International Business Management Students. Teaching in Higher Education 22(1): 15-29.

Matthews, K. E. (2016). Students as Partners as the Future of Student Engagement. RAISE: Student Engagement in Higher Education Journal 1(1). 
McCutcheon, G., \& Jung, B. (1990). Alternative Perspectives on Action Research. Theory into Practice 29(3): 144-51.

Mihans, R. J. II, Long, D. T., \& Felten, P. (2008) Power and Expertise: Student-faculty Collaboration in Course Design and the Scholarship of Teaching and Learning. International Journal for the Scholarship of Teaching and Learning 2(2): Article 16.

Available at: https://doi.org/10.20429/ijsotl.2008.020216

Mitchell, B. C. (2014). Increasing College Diversity.http://diverseeducation.com/article/66470/

Mitchell, D. Jr., Simmons, C, Y. \& Greyerbiehl, L. A. (Eds.) (2014). Intersectionality \& Higher Education Theory, Research, \& Praxis. Peter Lang.

Nash, J. C. (2008). Rethinking Intersectionality. Feminist Review 89: 1-15.

New, J. (2016, February). Get Ready for More Protests. Inside Higher Ed. https://www.insidehighered.com/news/2016/02/11/survey-finds-nearly-1-10-freshmenplan-participating-campusprotests?utm source $=$ Inside $\% 20$ Higher $\% 20$ Ed\&utm campaign $=e 83 \mathrm{~b} 403584$ DNU20160211\&utm medium=email\&utm term=0 1 fcbc04421-e83b403584-197314581

Ruff, C. (2016, March 16). The Mental and Academic Costs of Campus Activism. The New York Times. http://www.chronicle.com/article/The-MentalAcademicCosts $/ 235711$ ?key $=\mathrm{mYIHJm}-$ FLhhilah3qyiKc1F2uoVgpH7IgZWkn1GWqANQRkt5aEpTcmMwSUJLYmlmX1g5OGtU elhkeWRJU0s5WW9wNWxVTXBjZFFB

Schutt, R. K. (2016). Understanding the Social World: Research Methods for the 21st Century. Los Angeles: Sage Publications.

Simmons, J., Lowrey-Hart, R., Wahl, S. T., \& McBride, C. (2013, July). Understanding the AfricanAmerican Student Experience in Higher Education through a Relational Dialectics Perspective. doi:10.1080/03634523.2013.813631

Somekh, B., \& Zeichner, K. (2009). Action Research for Educational Reform: Remodelling Action Research Theories and Practices in Local Contexts. Educational Action Research 17(1): 5-21.

Strayhorn, T.L. (2012). College Students' Sense of Belonging: A Key to Educational Success for All Students. New York: Routledge.

Volk, S. (2017, April 23). New Student Activism: Stops on the Road to New Solidarities. Center for Teaching Innovation and Excellence. http://languages.oberlin.edu/blogs/ctie/2017/04/23/new-student-activism-stops-on-theroad-to-new-solidarities/

Walker, M. (2009). Pedagogy for Rich Human Being-ness in Global Times. In Global Inequalities and Higher Education: Whose Interests are You Serving?, edited by E. Unterhalter and V. Carpentier, 219-240. Palgrave Macmillan.

Wexler, E. (2016, June 9). Measuring Inclusivity. Inside Higher Ed. https://www.insidehighered.com/news/2016/06/09/survey-aims-measure-inclusivitycampus?utm source $=$ Inside + Higher + Ed\&utm campaign $=\mathrm{e} 969 \mathrm{f} 3 \mathrm{c} 3 \mathrm{e} 9-$

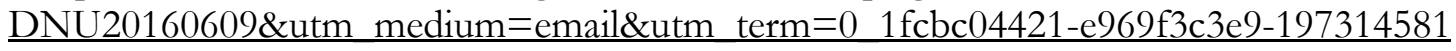




\title{
Appendix I: \\ Advocating Diversity in Higher Education \\ Spring 2016
}

\section{Interview Assignment \\ Advocating Diversity in Higher Education \\ Spring 2016 \\ Interview Assignment}

\begin{abstract}
"Quiet as it's kept" is also a figure of speech that is written, in this instance, but clearly chosen for how speakerly it is, how it speaks and bespeaks a particular world and its ambience. Further, in addition to its 'black fence' connotation, its suggestion of illicit gossip, of thrilling revelation, there is also, the 'whisper,' the assumption (on the part of the reader) that the teller is on the inside, knows something others do not, and is going to be generous with this privileged information. The intimacy I was aiming for, the intimacy between the reader and the page, could start up immediately because the secret is being shared, at best, and eavesdropped upon, at the least." -Toni Morrison, The Bluest Eye (Afterward)
\end{abstract}

Introduction:

Numerical diversity is an essential, but not sufficient condition for achieving diversity's true goals of inclusion. In an attempt to bring to the surface issues of diversity beyond representation, students have initiated campus-wide discussions focused on differences, improvement, tokenism, privilege, and community. In the absence of institutional support, often times these discussions become fruitless, and over-exhausted. As a result, many students feel that these conversations are circulated amongst students directly invested in effecting change, and seldom reaches their intended audiences. Meanwhile, others on the peripheries of these discussions feel they are not welcomed into the conversation. In this course, we recognize the importance of providing structural support for a diverse body of students once they enter the academy, thereby making diversity more than just a call for inclusion, but rather, a generative invitation for revision.

The purpose of this assignment is to create spaces in which members of the [names of college] community can speak in confidentiality about topics of diversity on their campuses, and also have their voices heard, and their experiences valued by participants in the course and beyond as part of a larger effort to facilitate more extensive and inclusive dialogue.

In this document you will find instructions for conducting short interviews designed to follow the journeys of students' experiences and encounters with "diversity" in higher education through the lens of their multifaceted identities. Each unique interview conducted will give voice to their individual perceptions, encounters, and experiences with diversity on campus. These interviews serve as a space where both the interviewer and interviewee can learn and grow from the exchange of experiences.

\section{Instructions:}

1. Find a member of the Bi-College community: Find a student, staff, or faculty member in the Bi-Co who will feel comfortable being a part of this confidential interview series. The purpose of 
this series is to give voice to a range of experiences, so try your best to look for someone whose story might not otherwise be heard.

Before having your interviewee commit to the interview, the each volunteer should be informed the interview is completely confidential, and their responses-with no names or other identifying information attached - will be shared with the class, and will be used as prompts for various writing assignments and class activities throughout the course.

2. Schedule a Meeting Place and Time: The interview should take no more than 30 minutes, but you should plan to meet with your interviewee for about 45 minutes (you might end up having extra questions after the interview, or a wonderful wrap-up discussion).

Meet in a space where the person will feel comfortable speaking. This can be in a quiet corner of a library, or in at a table in the Campus Center (I suggest somewhere with couches!). Your goal is to find or create a safe space where both you and your interviewee can comfortably share and talk for the duration of your interview.

3. Conduct the Interview!: For this interview, you will need to bring:

- A copy of the interview questions

- A device that can record the conversation for transcription later (ex. Phone, laptop, tape recorder $* *$ if needed, a recording device can be loaned from the library**)

- A timer to keep track of the conversation.

Prior to starting the interview, reiterate to the person that this interview is confidential, and to help to ensure confidentiality, they should refrain from using specifics, like names, when sharing personal stories.

Record the entire interview. Try and keep it between 15 and 30 minutes. The length of the interview may vary depending on how much the interviewee is willing to share, and how they want to answer the questions. Use your interview question sheet as a guide for the interview, and also as a note sheet for quotes and ideas you would like to revisit or remember.

Once the interview is over, feel free to share the attached sample interview with the person to show them how their interview will be presented and shared.

4. Transcribe the Interview: Transcribe the interview word for word into a Word document. Do not censor language in the interview unless it is a name or another identifier that could compromise interviewee's, or another person's, identity and confidentiality.

5. Format the Interview: Using your transcription notes, transfer your interviewee's responses into the Identity \& Diversity in Higher Ed Interview Series presentation template.

You will not be using all of your transcription notes. Use as many direct quotes as possible that best capture the heart of interviewee's response to the question. Make sure your formatting corresponds with the original interview questions, and that you are not paraphrasing or misquoting your interviewee. 
Once completed, send a copy of your formatted interview to your interviewee to make sure they are comfortable with its presentation, and if not, invite them to make edits, comments, and suggestions to the rough draft.

$\underline{\text { Identity \& Diversity in Higher Education Interview Questions }}$

(2-3 mins) How do you identify? (Tell them this list can include, but is not limited to: roles on campus, roles within their families, racial identities, ethnicities, gender, sexuality, etc.)

(2-3 mins) What does diversity look like to you on campus? How do you feel diversity works on campus? (How students, faculty, staff, the institution as a whole, campus culture, all engage notions of "diversity" on campus)

(5-10 mins) Describe a time/ encounter/or event where the culture/ environment of the campus negatively affirmed your identity/ or was unsupportive. (Interviewee can share a personal anecdote if they wish)

(5-10 mins) Describe a time where the culture/ environment of the campus positively affirmed your identity/ or was supportive. (Interviewee can share a personal anecdote if they wish)

(2-3mins) Where would you like to see it go from here? (back to question 2) What would you like to see change?

$\underline{\text { Identity \& Diversity in Higher Education Presentation Template }}$

I am...

To me, diversity on campus...

Times when my campus or its culture is unsupportive, or negatively affirms my identity

Times when my campus or its culture is supportive, or affirms my identity

What I'd like to see in the future... 